Original Research Article

\title{
Medication use pattern and quality assessment of psychiatry outpatient department prescriptions of a tertiary care hospital
}

\author{
Ayan K. Pati, Siddhartha Ghosh*
}

Department of Pharmacology, IQ City Medical College, Durgapur, West Bengal, India

Received: 11 November 2018 Accepted: 08 December 2018

\section{*Correspondence to: \\ Dr. Siddhartha Ghosh, Email: drsiddharthaghosh83@ gmail.com}

Copyright: (C) the author(s), publisher and licensee Medip Academy. This is an openaccess article distributed under the terms of the Creative Commons Attribution NonCommercial License, which permits unrestricted noncommercial use, distribution, and reproduction in any medium, provided the original work is properly cited.

\begin{abstract}
Background: Psychiatric illness is a major but often underreported health burden. The field of psychopharmacotherapy is continuously evolving therefore needs monitoring to prevent irrationality. In this setting, authors analyzed the prescribing pattern of psychotropic drugs while simultaneously monitoring prescription quality in a tertiary care teaching private hospital.

Methods: A 6 month-prospective observational study was conducted in psychiatry out-patient department. Prescription pattern was analyzed using World Health Organization (WHO) drug use indicators. The quality of the prescriptions was assessed as per prescription writing guidelines issued by The Department of Health and Family Welfare, Government of West Bengal.

Results: Of the 745 prescriptions analyzed, depression and psychosis constituted the bulk of diagnosed cases irrespective of any gender predominance. The average number of psychotropic drugs per prescription was 2.85 \pm 1.48 . Antidepressants, sedative-hypnotic and anxiolytics are most commonly prescribed drugs. $37.58 \%$ of psychotropic drugs were given as fixed dose combination, most common being risperidone with trihexyphenidyl. Only $2.91 \%$ of the drugs were prescribed in generic name whereas $53.99 \%$ were enlisted in national essential medicine list 2015. Polypharmacy and therapeutic duplication were noted in $41 \%$ and $26.84 \%$ of prescriptions and dose, duration and frequency were not mentioned in $2.68 \%, 53.02 \%$ and $19.00 \%$ of the prescription respectively.

Conclusions: Use of psychotropic drugs follows closely with different treatment guideline, though routine uses of central anticholinergics with atypical antipsychotics are not recommended. Despite high utilization of NLEM, more generic prescribing, correct prescription dosing schedule, avoidance of polypharmacy and non-Judicious use of multivitamin FDCs may significantly improve treatment outcome.
\end{abstract}

Keywords: Outpatients, Prescribing pattern, Psychiatry, Psychotropic drugs, Prescription audit

\section{INTRODUCTION}

Medication prescribing pattern around the world is not uniform. Demographic, cultural and environmental influences as well as availability of newer drugs and preferred choice of physicians in an area are few of the many factors for this variation. ${ }^{1}$ In a nutshell, the aim of analyzing prescribing pattern is to evaluate and promote rational prescribing by identifying extent, nature and determinants of drug exposure, monitoring the prescribing habit and any deviation thereof from standard treatment guidelines and suggesting modifications. ${ }^{2}$ Analysing prescribing quality and pattern via periodic assessment and review of ongoing clinical practice becomes an integral part to achieve that goal.

Mental illness is an enormous public health burden and a growing field where number of diagnosed cases are increasing, newer promising psychotropic molecules are employed more, and practice guidelines are constantly evolving based on current evidence. This leads to increased healthcare cost, decreased affordability, increased chances of polypharmacy and unwanted drug 
interactions. ${ }^{1}$ Thus, effectiveness and safety of the psychotropic drugs in the real-life situation needs continuous evaluation of prescribing pattern especially in the field of psychiatry.

With this background, the current study was conducted in a tertiary care hospital and private medical college in Eastern India not only to analyse the prescribing behaviour but also simultaneously assess the quality of prescriptions in the psychiatric out- patient department.

\section{METHODS}

A hospital-based prospective cross-sectional observational study of 6 months (January to June 2017) duration was carried out in outdoor patients of the psychiatry department of IQ City Medical College, Durgapur, West Bengal. Approval from Institutional Ethics Committee (IEC) was obtained, strict confidentiality was maintained and The Strengthening the Reporting of Observational Studies in Epidemiology (STROBE) guideline was followed in the preparation of protocol and the manuscript. ${ }^{3}$ Both new and follow up patients of all ages and both sexes suffering from a psychiatric illness and prescribed at least one drug were included in the study. Inpatients and referred patients were excluded from the study.

\section{Sample size}

A total of 745 prescriptions were analyzed as per the WHO recommendations on conducting DUS from medical databases/registries. ${ }^{4}$

\section{Sampling technique}

Purposive sampling method is used to recruit the patients fulfilling the eligibility criteria.

\section{Study procedure}

The data of the patients attending the Psychiatry OPD, during the period $25^{\text {th }}$ January to $30^{\text {th }}$ June was collected from the photocopies of the actual prescriptions obtained from Medical Record Department (MRD) of the hospital. Patient related information (age, sex and diagnosis) and drug-related information (drugs, dose, dosage form, route of administration) were recorded on a customized data collection sheet and analyzed in the Dept. of Pharmacology, IQ City Medical College by two independent investigators.

Patient details (age, gender, religion), prescription details (date, number of drugs, names of individual drugs, National List of Essential Medicine (NLEM), 2015 enlisted drugs, narrow therapeutic index drugs, dose, dosage form, dosing schedule, route, relationship with food, duration of treatment and interacting drugs), quality of the prescriptions (legibility, whether primary diagnosis mentioned or not, prescriber's identity, signature, use of non-standard abbreviations) were collected and evaluated with respect to World Health Organization- International Network for Rational Use of Drugs (WHO-INRUD) drug use indicators and prescription proforma of Standard Treatment Guideline (STG). ${ }^{4-6}$ Statistical analysis was done using Microsoft Excel 2007.

\section{RESULTS}

A total of 745 prescriptions were collected and analyzed from psychiatry OPD. There was no gender predominance in terms of psychiatric illnesses; $52.35 \%(n=390)$ and $47.65 \%(n=355)$ of the patients were male and females respectively. The disease burden was observed in the age range of 9-77years with a median of 37years. Primary diagnosis was mentioned in 265 cases, only symptoms in 385 cases and 95 cases were without diagnosis or symptoms. Out of the total 265 prescriptions where diagnoses were mentioned, depression and psychosis remain the top causes of morbidity. The distribution of psychiatric disorders among the diagnosed cases are shown in (Table 1).

Table 1: Distribution of psychiatric illness among diagnosed cases.

\begin{tabular}{|ll|}
\hline Diagnosis mentioned & Prescriptions \\
\hline Adjustment disorder & 5 \\
\hline Alcohol dependence & 5 \\
\hline Anxiety disorders & 15 \\
\hline Generalized anxiety disorder & 20 \\
\hline Obsessive compulsive disorders & 35 \\
\hline Depression & 90 \\
\hline Psychosis & 50 \\
\hline Mania & 15 \\
\hline Dissociative disorder & 5 \\
\hline Panic disorder & 5 \\
\hline Mental retardation & 10 \\
\hline Phobia & 5 \\
\hline Impulse control disorder & 5 \\
\hline Total & 265 \\
\hline
\end{tabular}

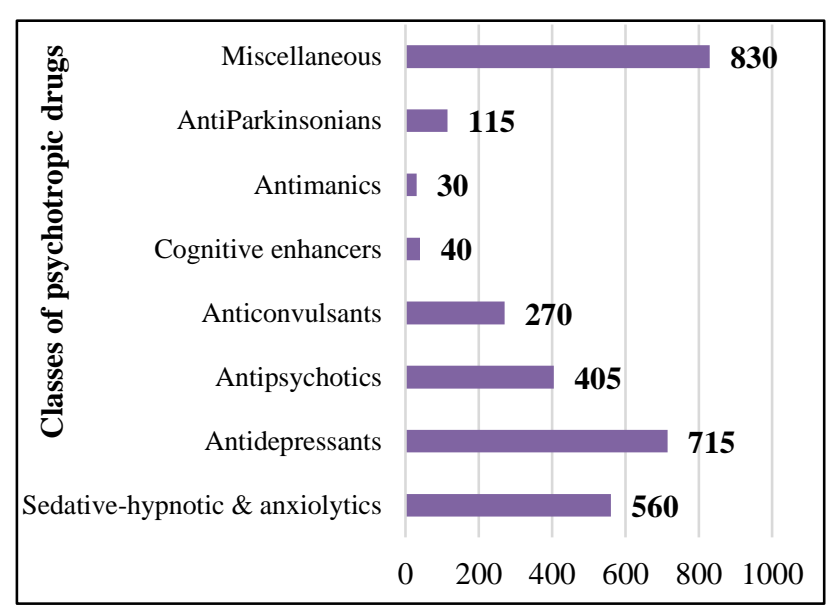

Figure 1: Distribution of psychotropic drug usage. 
A total of 2965 drugs were prescribed. Polypharmacy was practiced among 41\% ( $\mathrm{n}=305)$ of the prescriptions. Among psychotropic drugs, the frequency of prescribing antidepressants is highest $(33.65 \%, \mathrm{n}=715)$ followed by sedative-hypnotic and anxiolytic agents $(26.35 \%, \mathrm{n}=560)$, antipsychotics $(13.66 \%, \mathrm{n}=405)$, anticonvulsants $(9.1 \%$, $\mathrm{n}=270)$, antiparkinsonian $(3.88 \%, \mathrm{n}=115)$, cognitive enhancers $(1.35 \%, \mathrm{n}=40)$, and antimanic drugs $(1.01 \%$, $\mathrm{n}=30$ ). The class wise distribution of psychotropic drugs usage is depicted in (Figure 1).

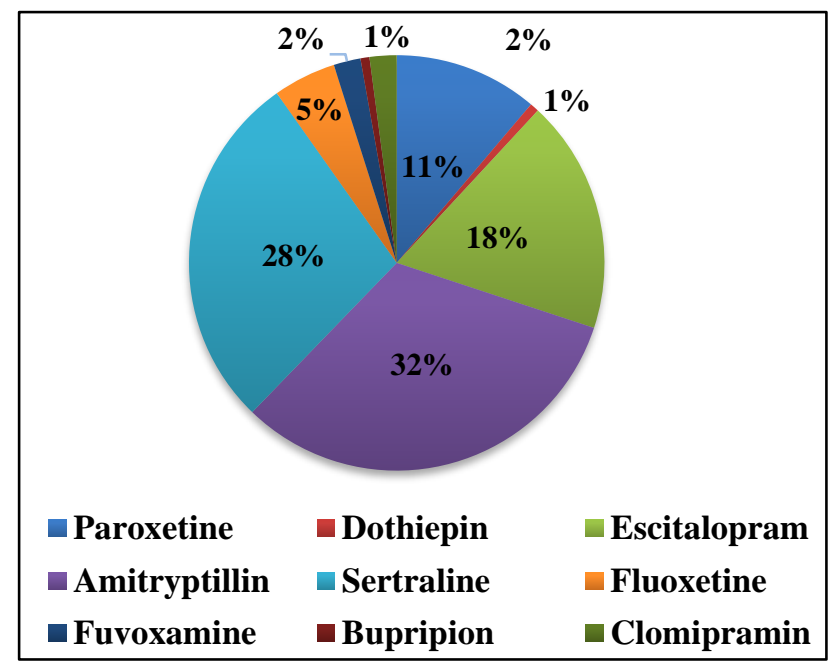

Figure 2: Utilization pattern of antidepressants.

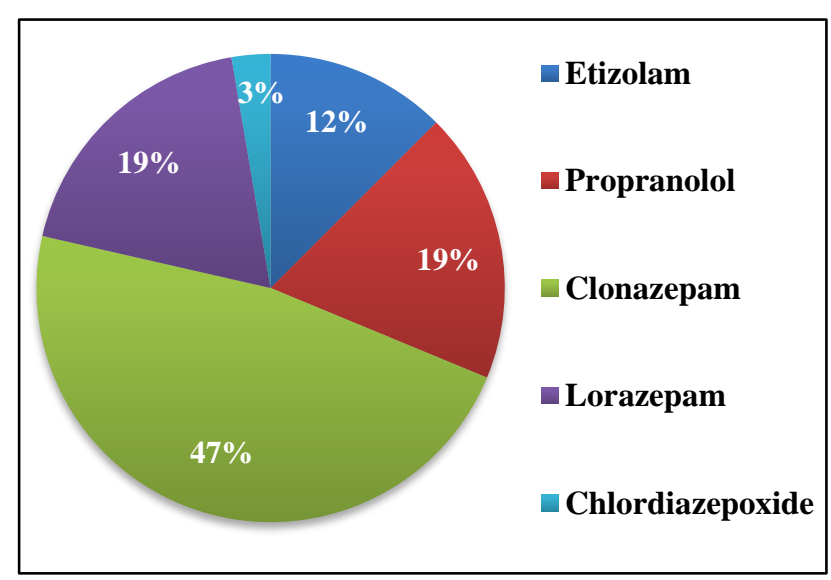

Figure 3: Utilization pattern of sedative-hypnotics.

Amitriptyline (32.16\%, $\mathrm{n}=230)$, sertraline $\quad(27.97 \%$, $\mathrm{n}=200)$, escitalopram $(18.18 \%, \mathrm{n}=130)$ are most frequently used antidepressants and clonazepam $(47.32 \%, \mathrm{n}=265)$, lorazepam, propranolol $(18.75 \%, \mathrm{n}=105$ each) and etizolam $(12.5 \%, \mathrm{n}=70)$ are the most commonly used sedative-hypnotics. The distribution pattern of choice of individual agents among antidepressants and sedativehypnotics classes are shown in (Figure 2 and Figure 3 ).

The other common comedications $(27.99 \%, \mathrm{n}=830)$ were methylcobalamine, folic acid, pyridoxine, nitroglycerine and multivitamins etc. Out of the 280 fixed dose combinations (FDC), 23.21\% $(n=65)$ were psychotropic drugs, $66.07 \% \quad(n=185)$ were vitamin supplements combinations and $10.71 \% \quad(n=30)$ were proton pump inhibitors and prokinetics. Most commonly used fixed dose combinations of psychotropic drugs were risperidone with trihexyphenidyl $(46.15 \%, \mathrm{n}=30)$, amitriptyline with chlordiazepoxide $(23.07 \%, \mathrm{n}=15)$, amitriptyline with pregabalin and escitalopram with flupenthixol $(15.38 \%, \mathrm{n}=$ 10 each). Most commonly used multivitamin combination was folic acid with pyridoxal phosphate and mecobalamin $(32.43 \%, \mathrm{n}=60) .5 .37 \%$ of the total drugs were narrow therapeutic index medications.

Table 2: Drug usage pattern in the study population.

\begin{tabular}{|ll|}
\hline Drug use indicators & Results \\
\hline $\begin{array}{l}\text { Average number of drugs per } \\
\text { prescription: Mean } \pm \text { SD }\end{array}$ & $3.98 \pm 1.78$ \\
\hline $\begin{array}{l}\text { Average number of psychotropic drugs } \\
\text { per prescription: Mean } \pm \text { SD }\end{array}$ & $2.85 \pm 1.48$ \\
\hline $\begin{array}{l}\text { Percentage of prescriptions containing } \\
\text { psychotropic FDCs }\end{array}$ & 37.58 \\
\hline $\begin{array}{l}\text { Percentage of drugs prescribed by generic } \\
\text { name }\end{array}$ & 2.91 \\
\hline $\begin{array}{l}\text { Percentage of drugs prescribed from } \\
\text { NLEM }\end{array}$ & 53.99 \\
\hline $\begin{array}{l}\text { Percentage of prescriptions with an } \\
\text { injection prescribed }\end{array}$ & 0.13 \\
\hline
\end{tabular}

Analysis of prescriptions by WHO-INRUD drug use indicators is provided in Table 2.

Table 3: Quality of prescription assessment.

\begin{tabular}{|ll|}
\hline Prescribing indicators & Results \\
\hline $\begin{array}{l}\text { Percentage of prescriptions not } \\
\text { mentioning dose of any drug }\end{array}$ & 2.68 \\
\hline $\begin{array}{l}\text { Percentage of prescriptions not } \\
\text { mentioning duration of any drug }\end{array}$ & 53.02 \\
\hline $\begin{array}{l}\text { Percentage of prescriptions not } \\
\text { mentioning frequency of any drug }\end{array}$ & 19.00 \\
\hline $\begin{array}{l}\text { Percentage of prescriptions with } \\
\text { therapeutic duplication }\end{array}$ & 26.84 \\
\hline
\end{tabular}

The quality of the prescriptions was assessed separately as per Standard Treatment Guideline (STG) Operational Manual for the Monitors/Assessors provided by Department of Health and Family Welfare, Govt. of West Bengal. Results of prescription quality analysis is depicted in (Table 3). All prescription had date, signature and overall legibility.

\section{DISCUSSION}

Neuropsychiatric disease burden is underrepresented in India due to lack of awareness, social stigma and various other factors. With the advent of evidence-based medicine, the field of neuropharmacology is revolutionized by newer drugs with novel mechanisms and off label use of conventional agents in various disorders. Analysis of 
prescriptions with respect to trend of psychotropic drug use as well as overall quality of prescribing not only gives valuable insight on current practices but also helps to reduce the chances of adverse drug reactions, unwanted drug interactions, medication errors, polypharmacy and thereby making the treatment cost-effective and rational. However, to date only a few studies have simultaneously evaluated prescription pattern and quality of the prescription both of which can help to prevent irrationality. Our study aims to assess this in a tertiary care hospital and private medical College in eastern India.

In present study, authors did not find any gender predominance regarding psychiatric consultation which is comparable to the previous studies. ${ }^{1,7,8}$ Most common diagnoses were depression followed by psychosis, obsessive compulsive disorders and anxiety. Average number of drugs per prescription was 3.98 but polypharmacy was higher than that found in similar studies. $^{8}$

SSRIs are recommended by current practice guidelines for mood disorders due to their better adverse effect profile. ${ }^{7,8}$ However, in this study, among the antidepressants, TCAs are prescribed more than SSRIs probably due to more severe and resistant cases were encountered in our tertiary care hospital. Atypical antipsychotics (olanzapine and quetiapine) are preferred over typical ones due to better adverse effects profile. Like other studies, benzodiazepines were very commonly prescribed anxiolytics. ${ }^{7,9}$ Though benzodiazepines have some addictive liability, easy availability and low cost make it preferred anxiolytic. In Present study, benzodiazepine was extensively used in various psychiatric conditions as adjunct. Short acting BZDs (clonazepam and lorazepam) were preferred. They have less dependence or withdrawal symptoms. This is in accordance with current guidelines which recommend use of a short acting agent for short-term (maximum 4 weeks) or intermittently in minimum effective doses. ${ }^{10}$ Use of generic medicine can substantially reduce the cost of therapy provided adequate quality is ensured. As compared to studies done in government hospitals, where generic prescribing has been made mandatory, private nature of our setup contributes to low level of generic prescribing. ${ }^{8}$ In our study, the only injectable prescribed was injection lorazepam for control of agitation. Proportion of drugs prescribed from NLEM was high promoting rational prescribing.

Percentage of prescriptions containing psychotropic FDCs are high and a combination of atypical antipsychotic with central anticholinergics (risperidone with trihexyphenidyl) was used most commonly to counteract extrapyramidal symptoms although less frequently seen with atypical antipsychotics. Use of central anticholinergics causes dry mouth, blurred vision, constipation, retention of urine. ${ }^{9}$ Furthermore, due to concerns over addition of central anticholinergics may itself aggravates tardive dyskinesia in some studies, WHO recommends not to routinely use anticholinergics in psychosis for prevention of extrapyramidal syndrome but to be used judiciously for short term in selected cases only. ${ }^{11}$

Most commonly used non-psychotropic comedications were methylcobalamine, folic acid, pyridoxal phosphate and their FDCs. This can be judiciously reduced by the prescribers to make the prescription more rational, costeffective and affordable to the patients.

Authors did not study patient's follow up prescriptions into consideration. Patient compliance, adverse drug reactions, cost of treatment, adherence to standard treatment guideline, rationality of prescribing with respect to diagnosis and comorbidity could not be assessed. Present study was done in a tertiary care private health facility in eastern India, which may not be a true representative sample of national figures. The non-availability of free and generic drugs in hospital pharmacy maybe a key factor influencing the prescribing behaviour. This study can serve as a basic framework on which future psychotropic drug utilization study can be carried out.

Funding: No funding sources

Conflict of interest: None declared

Ethical approval: The study was approved by the Institutional Ethics Committee

\section{REFERENCES}

1. Rode SB, Ajagallay RK, Salankar HV, Sinha U. A study on drug prescribing pattern in psychiatry outpatient department from a tertiary care teaching hospital. Int J Basic Clin Pharmacol. 2017 Jan 24;3(3):517-22.

2. Gupta N, Sharma D, Garg SK, Bhargava VK. Auditing of prescriptions to study utilization of antimicrobials in a tertiary hospital. Indian journal of pharmacology. 1997 Nov 1;29(6):411-5.

3. Elm E Von, Altman DG, Egger M, Pocock SJ, Peter C, Gøtzsche P, et al. guidelines for reporting observational studies Strengthening the reporting of observational studies in epidemiology (STROBE) statement: guidelines for reporting observational studies. Br Med J. 2007;335(October):19-22.

4. World Health Organization. How to investigate drug use in health facilities. 1993:1-92. Available at: http://apps.who.int/medicinedocs/pdf/s2289e/s2289e. pdf.

5. Report of the Core-Committee for Revision of National List of Essential Medicines. November 2015. Available http://cdsco.nic.in/WriteReadData/NLEM-

2015/Recommendations.pdf. Accessed 1 November 2018.

6. Standard Treatment Guidelines: For Primary Health Care facilities. Second edition. Department of Health and Family Welfare. Government of West Bengal. February 2011. Available at: http://www.ihfwkolkata.org/stg/stg2.html\#. Accessed November 1, 2018. 
7. Piparva K, Singh A, Trivedi H, Parmar D, Gajera M Drug utilization study of psychotropic drugs in outdoor patients in a teaching hospital. Indian J Psychol Med. 2011;33(1):54.

8. Mukherjee S, Sen S, Chatterjee SS, Biswas A. Prescribing pattern of psychotropic medications in psychiatry outpatients at a tertiary care teaching hospital in India: a prospective cross-sectional study. Int J Hospital Res. 2014; 3(3):113-22.

9. Thakkar KB, Jain MM, Billa G, Joshi A, Khobragade AA. A drug utilization study of psychotropic drugs prescribed in the psychiatry outpatient department of a tertiary care hospital. J Clin Diagnostic Res. 2013;7(12):2759-64.
10. Ashton H. Guidelines for the rational use of benzodiazepines. Drugs. 1994 Jul 1;48(1):25-40.

11. Role of anticholinergic medications in patients requiring long-term antipsychotic treatment for psychotic disorders. Available at: www.who.int/mental_health/mhgap/evidence/psycho sis/q6/en/. Accessed November 1, 2018.

Cite this article as: Pati $\mathrm{AK}$, Ghosh $\mathrm{S}$. Medication use pattern and quality assessment of psychiatry outpatient department prescriptions of a tertiary care hospital. Int J Basic Clin Pharmacol 2019;8:211-5. 